\title{
BARTHOLOMEUSZ (Tessa J), DE SILVA (Chandra R.), eds., Buddhist Fundamentalism and Minority Identities in Sri Lanka
}

Albany (N.Y.), State University of New York Press, 1998, 212 p.

\section{Éric Meyer}

\section{OpenEdition}

Journals

Édition électronique

URL : http://journals.openedition.org/assr/20731

DOI : 10.4000/assr.20731

ISSN : $1777-5825$

Éditeur

Éditions de l'EHESS

Édition imprimée

Date de publication : 1 juin 2001

Pagination : 68-69

ISBN : 2-222-96704-X

ISSN : 0335-5985

\section{Référence électronique}

Éric Meyer, «BARTHOLOMEUSZ (Tessa J), DE SILVA (Chandra R.), eds., Buddhist Fundamentalism and Minority Identities in Sri Lanka », Archives de sciences sociales des religions [En ligne], 114 I avril-juin 2001, document 114.2, mis en ligne le 19 août 2009, consulté le 21 septembre 2020. URL : http:// journals.openedition.org/assr/20731; DOI : https://doi.org/10.4000/assr.20731 


\section{BARTHOLOMEUSZ (Tessa J), DE SILVA (Chandra R.), eds., Buddhist Fundamentalism and Minority Identities in Sri Lanka}

Albany (N.Y.), State University of New York Press, 1998, 212 p.

\section{Éric Meyer}

\section{RÉFÉRENCE}

BARTHOLOMEUSZ (Tessa J), DE SILVA (Chandra R.), eds., Buddhist Fundamentalism and Minority Identities in Sri Lanka, Albany (N.Y.), State University of New York Press, 1998, $212 \mathrm{p}$.

1 Cet important ouvrage rassemble une dizaine de contributions abordant sous un angle théorique nouveau un sujet déjà largement défriché par K. Malalgoda (Buddhism in Sinhalese Society, Berkeley, University of California Press, 1976), G. Obeyesekere (avec R. Gombrich, Buddhism Transformed: Religious Change in Sri Lanka, Princeton, Princeton University Press, 1988), S.J. Tambiah (Buddhism Betrayed? Religion, Politics and Violence in Sri Lanka, Chicago, Chicago University Press, 1992 [cf. Arch. 82.83]) et H. L. Seneviratne (The Work of Kings: The New Buddhism in Sri Lanka, Chicago, Chicago University Press, 1999) (en français, cf. É. Meyer, Sri Lanka entre particularismes et mondialisation, Paris, La Documentation Française, 2001).

2 Il s'agit de s'interroger sur la genèse et les caractéristiques du néo-bouddhisme Sri lankais, dont l'Anagarika Dharmapala (1864-1933) fut l'initiateur, et qui s'est traduit sur le plan politique par l'essor du communalisme singhalais- bouddhique depuis 1956. La nouveauté de l'apport réside d'abord dans l'application (trop mécanique à notre sens) à ce champ d'étude de la problématique des fondamentalismes mise à la mode dans les années 1990 par le vaste programme de l'Université de Chicago piloté par Martin Marty 
et Scott Appleby. Le second volet du projet consiste à analyser la reconfiguration des identités religieuses minoritaires (hindoues, musulmanes et chrétiennes) comme une réponse au défi du fondamentalisme bouddhiste.

3 Une question préalable est celle de la validité du concept de fondamentalisme appliqué au bouddhisme. La référence à un passé où le bouddhisme aurait été pur de toute accrétion est un thème familier du theravada singhalais, dont l'histoire est rythmée d'accès d'épuration. D'autre part, le mouvement de rénovation de la pratique religieuse entrepris à l'initiative de laïcs à la fin du XIX $\mathrm{X}^{\mathrm{e}}$ siècle se voulait moderniste (il s'adressait à une bourgeoisie en plein essor et modelait ses méthodes d'action sur celles des missions protestantes), mais il était en même temps soucieux de rétablir un ordre ancien où le bouddhisme aurait joui d'un statut privilégié et où les moines auraient dicté aux détenteurs de l'autorité séculière les principes de leur action.

Or les textes auxquels se réfèrent les fondamentalistes singhalais ne sont pas les textes canoniques du Triple Recueil (Tripitaka) mais ceux de la grande chronique monastique de l'île (Mahavamsa) dont ils font la charte du «bouddhisme dans un seul pays ». Plus que de fondamentalisme, il faut parler de communa-lisme ou de sub-nationalisme amalgamant religion, langue et territoire, dans un discours identitaire qui dénie aux minorités non bouddhistes singhalaises un statut égal. La langue et le passé commun, ingrédients classiques du nationalisme, ont autant de place que la religion dans cette construction.

5 Les contributions de Bond et de de Silva posent la question de la cohérence des positions de ceux qu'ils qualifient de fondamentalistes : ainsi les moines sont loin de tous partager la conviction que l'État doit se faire le protecteur du bouddhisme : ce sont plus souvent les politiciens qui instrumentalisent le bouddhisme à des fins de conquête ou de conservation du pouvoir, et les laïcs qui, à l'instar de Dharmapala, s'arrogent le droit de parler au nom du bouddhisme. Le retour aux textes qu'implique la notion de fondamentalisme peut d'ailleurs conduire à remettre radicalement en cause la position des communalistes. L'actuelle présidente, Chandrika Kumaratunga, cherche dans l'enseignement originel du Bouddha des arguments en faveur d'un retour de Sri Lanka à la coexistence pacifique entre les communautés qui la composent.

6 L'analyse du devenir des minorités religieuses à Sri Lanka est éclairant par la diversité des situations qu'elle fait apparaître. Dans le cas des catholiques (étudiés par Stirrat) et des anglicans (T.B.), à la période coloniale, l'adhésion au christianisme représentait une marque identitaire assez forte pour l'emporter sur d'autres critères. Avec l'émergence du nationalisme singhalais, la décolonisation, puis la généralisation de l'enseignement en langues vernaculaires, les chrétiens firent peu à peu primer leur identité singhalaise ou tamoule selon les cas, sans que pour autant les (re)conversions au bouddhisme ou à l'hindouisme se multiplient.

7 Par contre les musulmans (étudiés par De Munck) refusèrent de se fondre dans la communauté tamoule dont ils parlaient généralement la langue, et obtinrent pour leurs écoles un statut séparé. En outre, à la fin du XXe siècle se développa dans la bourgeoisie musulmane un mouvement fondamentaliste vite encadré par la Tablighi Jama’at, qui entreprit d'éradiquer les pratiques soufi, générales en milieu rural. Il n'apparaît pas que cette démarche ait été l'effet d'une réponse consciente à l'affirmation du bouddhisme politique, mais elle pourrait conduire à terme à l'affrontement de deux fondamentalismes. 
8 Quant à l'hindouisme des Tamouls de Sri Lanka, il ne fait pas l'objet d'une étude poussée. Il ne s'y produit rien de comparable aux efforts déployés en Inde pour imposer une unité de vues et d'action aux adeptes de cultes très divers. L'hindouisme n'a aucune part aux origines du mouvement séparatiste tamoul, dont un nombre important de promoteurs sont d'origine chrétienne. Jeganathan, étudiant les Tamouls vivant dans le sud majoritairement singhalais, et Hollup, dans le cas des ouvriers tamouls des plantations, suggèrent que ces deux groupes s'identifient à travers des représentations qui font d'eux des victimes désignées d'une majorité singhalaise bouddhiste détentrice $\mathrm{du}$ pouvoir. On est loin du propos initial de l'ouvrage, et par comparaison avec la situation indienne, il eût été intéressant de s'interroger sur l'inexistence du militantisme hindou à Sri Lanka. Holt propose en conclusion de restreindre l'emploi du concept de fondamentalisme, le bouddhisme singhalais conservant selon lui son aptitude ancestrale à l'absorption des pratiques religieuses hindoues, en dépit de son instrumentalisation par deux générations de politiciens singhalais opportunistes. 